\title{
Gengivite-estomatite linfoplasmocitária felina: relato de caso
}

\section{Feline lymphoplasmacytic gingivostomatitis: case report}

\section{Resumo}

O complexo gengivite-estomatite-faringite linfoplasmocitária é uma doença comum em gatos e de caráter crônico, caracterizada pela inflamação, ulceração e proliferação dos tecidos moles da boca e é uma das doenças mais comuns em gatos, juntamente com a doença periodontal. O caso clínico descrito trata de um felino, fêmea, de três anos, tratado de maneira conservativa por cerca de quatro meses com medicações (antibióticos e cortisona via oral). Com a recidiva das lesões, optou-se, num segundo momento, pelo tratamento cirúrgico, com a remoção de todos os dentes molares e pré-molares do animal, obtendo-se assim a resolução da enfermidade até o presente momento.

\section{Summary}

The feline lymphoplasmacytic gingivostomatitis is a common chronic condition in cats and it is characterized by inflammation, ulceration and proliferation of the soft tissues of the mouth. It's one of the most common diseases in cats, as well as the periodontal disease. The clinical case described is about a three years old feline, female, that had been treated conservatively for about four months with medications (antibiotics and cortisone orally). With the recurrence of the lesions, the surgical treatment has been chosen, with removal of all molars and premolars of the animal, thus obtaining the resolution of the disease to date. 
Vanice Correto Dutra Allemand ${ }^{1}$

Ricardo Radighieri ${ }^{1}$

Carla Alice Bearl ${ }^{1}$
Rua Coronel Lisboa, 550, Vila Mariana

CEP: 04020-041 - São Paulo-SP

\section{Introdução}

O complexo gengivite-estomatite-faringite linfoplasmocitária

Gatos. Gengivite. Ulceras orais. Estomatite.

\section{Keywords}

Cats. Gingivitis. Oral ulcers. Stomatitis. (GEFLP) é uma doença comum em gatos e de caráter crônico, caracterizada pela inflamação, ulceração e proliferação dos tecidos moles da boca (BAIRD, 2005; LYON, 1990). É uma das causas mais comuns de afecção oral em gatos, juntamente com a doença periodontal (HEALEY et al., 2007). Pode estar associada a esta afecção a lesão de reabsorção dentaria felina, que ocorre devido a estimulação inflamatória primária da reabsorção dos dentes (NIZA; MESTRINHO; VILELA, 2004).

A gengivite-estomatite-faringite linfoplasmocitária (GEFLP) é uma doença idiopática, mas acredita-se que seja multifatorial com um componente imunomediado, seja por resposta deficiente do sistema imunológico do hospedeiro aos antígenos presentes na cavidade oral, seja por resposta imunológica exacerbada a eles (LYON, 2005; WIGGS, 2009).

$\mathrm{O}$ tratamento para a gengivite-estomatite-faringite linfoplasmocitária deve ser individualizado e, dependendo do caso, deve ser associado aos tratamentos clínico e cirúrgico. Ainda assim, as recidivas são comuns.

\section{Etiopatogenia}

A GEFLP caracteriza-se por uma resposta inflamatória local ou difusa, responsável pelo aparecimento de lesões ulceradas e proliferativas na cavidade oral. Os pacientes que apresentam a GEFLP parecem ter uma desordem imunológica, o que poderia justificar a apresentação de infecções bacterianas e virais concomitantes. 
NIZA; MESTRINHO; VILELA, 2004, sugerem predisposição racial nas raças: Siamês; Abissínio; Persa; Himalaio; e Birmanesa. Alguns animais apresentam sinais da doença muito jovens, logo após o aparecimento dos dentes decíduos, e geralmente persistem por toda a vida do animal. Nestes casos, acredita-se que haja infecção placentária ou condições imunes hereditárias que contribuam para o aparecimento da doença (WIGGS, 2009).

A GEFLP pode ser causada por qualquer estimulo inflamatório continuo nas gengivas do animal (NIZA; MESTRINHO; VILELA, 2004). O organismo dos animais acometidos tende a responder excessivamente aos ativadores de linfócitos B policlonais, como antígenos virais e bacterianos e apresentam um aumento das concentrações séricas de IgG, IgM e IgA e albumina. A sua concentração salivar de IgA também é menor que a observada em gatos sem a doença (SIMS; MONCLA; PAGE, 1990; NIZA; MESTRINHO; VILELA, 2004). Consequentemente, verifica-se a existência de uma resposta inflamatória insuficiente para combater os antígenos virais e bacterianos, mas suficientemente expressiva para produzir inflamação crônica local. Embora a participação viral na etiologia da doença (como calicivírus, coronavírus felino, herpesvírus, FIV e FeLV) tenha sido aventada, a correlação do surgimento da GEFLP com a presença de agentes infecciosos não foi confirmada por Quimby et al., 2008. Contudo Lommer e Verstraete (2003) observaram que $88 \%$ dos gatos que apresentavam gengivo-estomatite crônica eliminavam, concomitantemente, calicivírus e herpesvírus. Também foi observado aumento da população bacteriana anaeróbia oral (Bacterioides spp., Peptostreptococcus sp., Fusobacterim spp., Actinobacillus actinomycetemcomitans e algumas espiroquetas) (NIZA; MESTRINHO; VILELA, 2004; WIGGS, 2009). Entretanto, muitas destas bactérias também estão presentes em gatos assintomáticos. A alergia alimentar também já foi implicada na etiopatogenia da doença (NIZA; MESTRINHO; VILELA, 2004).

\section{Sinais e Sintomas Clínicos}

Os sinais clínicos variam com a gravidade das lesões e incluem: inapetência; anorexia; disfagia; halitose; ptialismo; dor; perda de peso e; desidratação. Também são relatados pateamento da face, redução de hábitos de toalete, piodermite de prega labial, dificuldade de apreensão de alimento, alteração de preferência de alimento (o animal passa a preferir alimentos macios) e linfoadenopatia submandibular (NIZA; MESTRINHO; VILELA, 2004; LYON, 2005).
Os animais acometidos apresentam lesões eritematosas, ulcerativas, proliferativas acometendo a gengiva, arcos glossopalatinos (região de fauces), língua, palato, lábios e mucosa bucal. Em alguns casos observa-se também processo de reabsorção odontoclástica felina e consequente queda de dentes (NIZA; MESTRINHO; VILELA, 2004; LYON, 2005).

\section{Diagnóstico}

O diagnóstico definitivo é estabelecido por biópsia e histopatológico das lesões. O histopatológico revela a presença de infiltrado linfocítico-plasmocítico. Alguns neutrófilos e eosinófilos podem estar presentes. Este exame também exclui outras causas de gengivo-estomatite como: tumores; doença periodontal; granuloma; eosinofílico e; doenças autoimunes como o pênfigo vulgaris; lúpus eritematoso; vasculite por hipersensibilidade; eritema multiforme e; necrose epidérmica tóxica (NIZA; MESTRINHO; VILELA, 2004; WIGGS, 2009).

O hemograma pode apresentar leucocitose e neutrofilia. A hiperproteinemia secundária à hiperglobulinemia é observada na metade dos gatos com GEFLP (NIZA; MESTRINHO; VILELA, 2004). Inflamações por FIV e FeLV podem levar à doença inflamatória oral, porém os gatos acometidos são, em sua maioria, negativos para FIV ou FeLV (BELLOWNS, 2008). Pode-se ainda fazer a pesquisa do calicivírus por amostras colhidas da região orofaríngea com zaragatoa (LOMMER; VERSTRAETE, 2003; WIGGS, 2009).

\section{Tratamento}

Até o momento não existe tratamento definitivo para a GEFLP. Trata-se de uma doença crônica, com reagudizações frequentes. Os protocolos terapêuticos envolvem abordagem médica, cirúrgica, ou a combinação de ambas, e devem objetivar a melhoria da qualidade de vida do animal e não necessariamente a remissão completa das lesões. As respostas ao tratamento são muito variáveis e de duração imprevisível. Portanto a terapêutica deve ser individualizada (NIZA; MESTRINHO; VILELA, 2004).

A primeira abordagem terapêutica é a realização do tratamento periodontal completo, incluindo a extração dos dentes acometidos por doença periodontal graus 3 e 4 e daqueles acometidos por lesão de reabsorção odontoclástica. Deve ser associada antibioticoterapia para diminuir a presença de antígenos bacterianos. Os antibióticos de primeira escolha incluem: Amoxicilina; Amoxicilina/Clavulanato; Doxiciclina; Enrofloxacina 
e; a associação Espiramicina e Metronidazol (BAIRD, 2005; WIGGS, 2009).

A terapia com corticosteroides na dose de 1 a $2 \mathrm{mg} /$ $\mathrm{kg}$ (inicialmente a cada $12 \mathrm{~h}$ e depois reduzindo até a mínima dose eficaz), pode ser benéfica (NIZA; MESTRINHO; VILELA, 2004).

Os dentes do animal devem ser frequentemente higienizados pelo proprietário e podem ser utilizadas dietas que reduzam a formação de cálculos e que sejam simultaneamente hipoalergênicas. Em casos graves é indicada a extração de todos os dentes distais aos dentes caninos e incisivos. Ainda assim, pode haver recidiva do quadro, sendo necessária a associação de terapia medicamentosa com drogas imunossupressoras: clorambucil $\left(2 \mathrm{mg} / \mathrm{m}^{2}\right.$ ou 0,1 a $0,2 \mathrm{mg} / \mathrm{kg} / \mathrm{SID}$ até uma resposta e depois reduzir para a cada $48 \mathrm{~h}$ ); ciclofosfamida $\left(50 \mathrm{mg} / \mathrm{m}^{2}\right.$ VO por 4 dias, seguido de interrupção por 3 dias). Deve-se fazer o controle do hemograma semanalmente durante o primeiro mês e em caso de imunossupressão intensa (contagem de neutrófilos abaixo de $3000 / \mu \mathrm{l}$ ), a terapia deve ser suspensa ou diminuída (WIGGS, 2009).

$\mathrm{O}$ interferon alfa recombinante humano tem sido usado no tratamento da GEFLP, principalmente devido ao seu papel imunomodulador. A dose é de 30 UI por dia, via oral. Administra-se por sete dias, seguido de um intervalo de sete dias sem medicação (WIGGS, 2009).

$\mathrm{O}$ interferon recombinante felino é um polipeptídio que intervém na modulação antigênica da superfície celular, na produção de anticorpos e na regulação da produção de citoquinas anti e pró-inflamatórias e inibe produção de angiogenese. Tem-se observado melhora da GEFLP com a utilização deste produto. O interferon não se encontra à venda no Brasil (NIZA; MESTRINHO; VILELA, 2004; SOUTHERDEN; GORREL, 2007).

Podem ser usados ainda: a lactoferrina bovina topicamente, na dose de $40 \mathrm{mg} / \mathrm{kg} / \mathrm{SID}$; Sais de Ouro; Laser de $\mathrm{CO}_{2}$; Acetato de Megestrol (1mg/kg) e; Levamisol (NIZA; MESTRINHO; VILELA, 2004).

\section{Caso Clínico}

O felino de três anos, fêmea, castrada, foi atendido no Centro veterinário Pet Care com histórico de salivação intensa e perda de peso havia cerca de duas semanas. O animal já fora tratado dois meses antes por colega, que suspeitara de infecção por retrovirus (FIV ou FeLV). Os proprietários relatavam diminuição de apetite desde então e negavam outras alterações. Os contactantes eram assintomáticos. Ao exame físico observou-se mucosas normocoradas, intensa gengivite e estomatite, com eritema, ulceração, edema e secreção espessa em região arcos glossofaríngeos. Estava hidratado, sua temperatura era de $38,7^{\circ} \mathrm{C}$, não foram observadas alterações à ausculta, nem à palpação abdominal. $\mathrm{O}$ hemograma e perfil bioquímico estavam inalterados e as sorologias para FIV e FeLV foram negativas. $\mathrm{O}$ animal fora tratado para micoplasmose há um ano. Foi prescrito tratamento com Espiramicina e Metronidazol, Predinisolona (o,5mg/kg/ SID) e alimentação pastosa. Foi solicitado agendamento de tratamento periodontal, biópsia da lesão e extração de todos os dentes caudais aos caninos. $\mathrm{O}$ animal retornou somente um mês depois, e o proprietário relatava recidiva do quadro apos período da melhora com as medicações que haviam sido prescritas. Foi então prescrito Predinisolona e Doxiciclina 5mg/kg/ BID.

O animal retornou após 15 dias, apresentando redução dos sintomas orais. Diminuiu-se então a dose da Predinisolona para $1 \mathrm{mg} / \mathrm{kg} /$ SID.

Após a diminuição da dose da Predinisolona, houve recidiva dos sintomas orais (Figura 1), então o proprietário optou pelo tratamento cirúrgico, que incluiu a biópsia da lesão e a remoção de todos os dentes distais aos caninos, além do tratamento periodontal (Figura 2).

O histopatológico foi compatível com gengivite linfoplasmocitaria severa. Foi então mantido o tratamento com Predinisolona ( $2 \mathrm{mg} / \mathrm{kg} / \mathrm{sid})$.

$\mathrm{O}$ animal retornou após um mês, apresentando melhora significativa das lesões orais (Figura 3).

Atualmente o animal está sendo medicado com a Predinisolona, contudo, está sendo submetido à diminuição das doses a fim de suspender a medicação, ou de realizar uma dose mínima de manutenção.

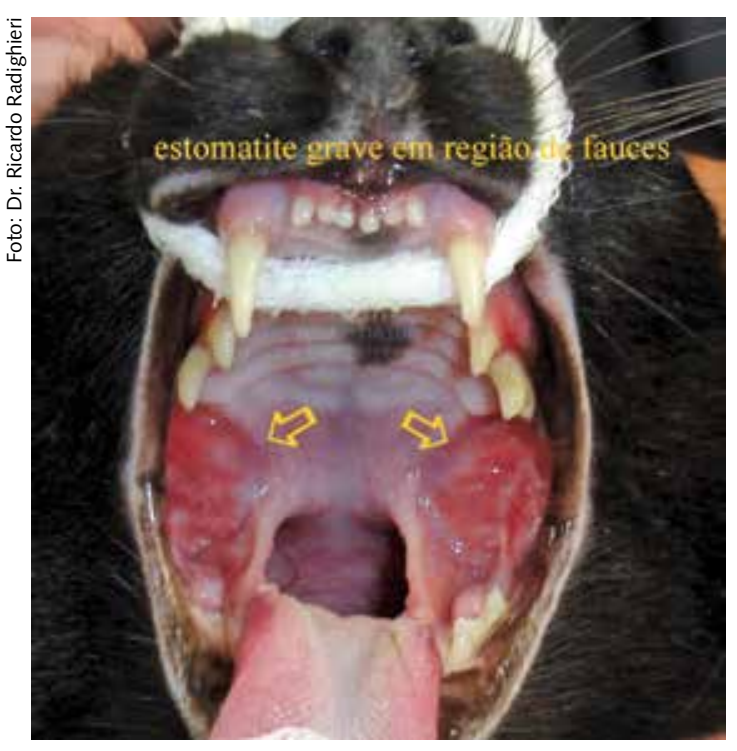

FIGURA 1 - Faucite grave 


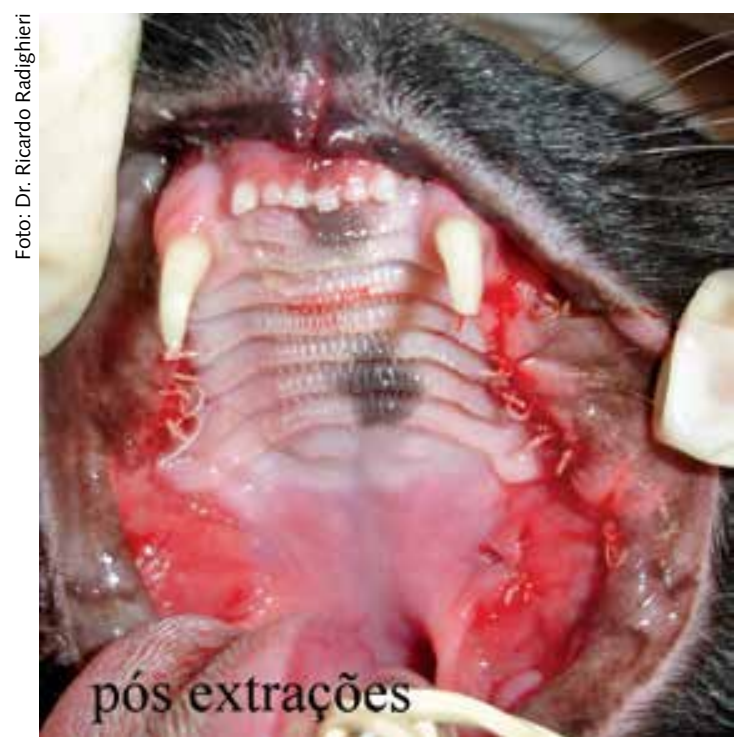

FIGURA 2 - Logo após extrações

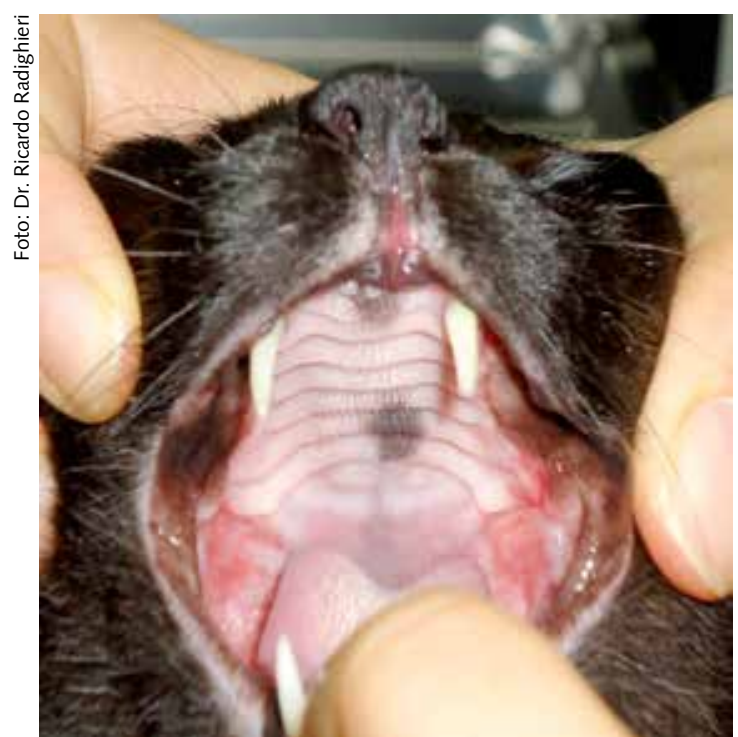

FIGURA 3 - Um mês após procedimento cirúrgico

\section{Discussão}

$\mathrm{O}$ animal atendido foi tratado inicialmente com antibioticoterapia e cortisona, o que resultou em melhora dos sinais clínicos e sintomas, durante um curto período de tempo. Esta resposta positiva pode ter sido associada à diminuição da carga antigênica oral, que nos animais predispostos ao desenvolvimento da gengivite linfopasmocitaria são um gatilho para o desenvolvimento de uma resposta inflamatória exacerbada (NIZA; MESTRINHO; VILELA, 2004).

A utilização concomitante da predinisolona em dose baixa também auxiliou na diminuição da resposta inflamatória. A recidiva foi observada alguns dias após a suspensão do antibiótico e uma dose mais alta da predinisolona foi prescrita, com melhora das lesões, provavelmente devido à imunossupressão. Como apenas isso não foi suficiente para manter o animal assintomático, optou-se pelo tratamento periodontal (sendo que neste animal a doença periodontal era quase inexistente, conforme pode ser observado na Figura 1) e, concomitantemente, a remoção de todos os molares e pré-molares, conforme indicado na literatura em casos mais graves da doença (WIGGS, 2009). Este foi o tratamento mais efetivo até o presente momento, permitindo a redução da dose da predinisolona com sucesso.

\section{Conclusão}

A gengivite estomatite linfoplasmocitaria severa é uma doença muito comum em felinos e de prognóstico reservado. No caso descrito foi necessária a extração de todos os dentes pré-molares e molares do animal, associado à terapia medicamentosa, para o controle da doença pois somente a terapia medicamentosa imunossupressora não foi suficiente. Entretanto, como se trata de uma doença de difícil controle e cura, o objetivo do tratamento está sendo a melhoria da qualidade de vida do animal e a ausência de sintomas e não a cura completa das lesões. O proprietário foi alertado para a possibilidade de recidivas, e está ciente de que se elas ocorrerem haverá a necessidade da associação de drogas imunomoduladoras ao tratamento.

\section{Referências}

1. BAIRD K. Lymphoplasmacytic gingivitis in a cat. Canadian Veterinary Journal, v. 46, n. 6, p. $530-532,2005$

2. BELLOWNS, J. Gengivite e faringite linfoplasmocitarias. In: TILLEY, L. P.; SMITH JR., F. W. K. Consulta veterinária em 5 minutos espécies canina e felina. Barueri: Manole, 2008. 632 p.

3. CORBEE, R. J.; BOOIJ-VRIELING, H. E.; VAN DE LEST, C. H.; PENNING, L. C.; TRYFONIDOU, M. A.; RIEMERS, F. M.; HAZEWINKEL, H. A. Inflammation and wound healing in cats with chronic gingivitis/stomatitis after extraction of all premolars and molars were not affected by feeding of two diets with different omega-6/omega-3 polyunsaturated fatty acid ratios. Journal of Animal Physiology and Animal Nutrition, v. 96, n. 4, p. 671-80, 2012.

4. CRYSTAL, M. A. Gengivite/Estomatite/Faringite. In: NORWORTHY, G. D.; CRYSTAL M. A.; TILLEY L. P. O paciente felino. São Paulo: Roca, 2009. p. 117-118.

5. HARLEY, R.; GRUFFYDD-JONES, T. J.; DAY, M. J. Salivary and serum immunoglobulin levels in cats with chronic gingivostomatitis. Veterinary Record, v. 152, p. 125-129, 2003

6. HEALEY, K. A. E.; DAWSON, S.; BURROW, R.; CRIPPS, P.; GASKELL, C. J.; HART, A.; PINCHBECK, G. L.; RADFORD, A. D.; GASKELL, R. M. Prevalence of feline chronic gingivo-stomatitis in first opinion veterinary practice. Journal of Feline Medicine and Surgery, v. 9, n. 5, p. 373-381, 2007. 
7. LOMMER, M. J.; VERSTRAETE, F. J. M. Concurrent oral shedding of feline calicivirus and feline herpesvirus 1 in cats with chronic gingivostomatitis. Oral Microbiology and Immunology, v. 18, n. 2, p. 131-134, 2003.

8. LYON, K. F. The differential diagnosis and treatment of gingivitis in the cat. Problems in Veterinary Medicine, v. 2, n. 1, p. 137-151, 1990.

9. LYON, K. F. Gingivostomatitis. Veterinary Clinics of North America: small animal practice, v. 35, n. 4, p. 891-911, 2005.

10. NELSON, R. W.; COUTO, C. G. Distúrbios da cavidade oral, faringe e esôfago. In: NELSON, R. W.; COUTO, C. G. Medicina interna de pequenos animais. 3. ed. Rio de Janeiro: Elsevier, 2006. p. 395-396.

11. NIZA, M. M. R. E.; MESTRINHO, L. A.; VILELA, C. L. Gengivo-estomatite crônica felina - um desafio clínico. Revista Portuguesa de Ciências Veterinárias, v. 99, n. 551, p. 127-135, 2004.
12. PEDERSEN, N. C. Inflammatory oral cavity diseases of the cat. Veterinary Clinics of North America: small animal practice, v. 22, n. 6 p. 1323-1345, 1992.

13. QUIMBY, J. M.; ELSTON, T.; HAWLEY, J.; BREWER, M.; MILLER, A.; LAPPIN, M. R. Evaluation of the association of Bartonella species, feline herpesvirus 1, feline calicivirus, feline leukemia virus and feline immunodeficiency virus with chronic feline gingivostomatitis. Journal of Feline Medicine \& Surgery, v. 10, n. 1, p. 66-72, 2008.

14. SIMS, T. J.; MONCLA, B. J.; PAGE, R. C. Serum antibody response to antigens of oral gram-negative bacteria by cats with plasma cell gingivitis-pharyngitis. Journal of Dental Reserch, v. 69, n. 3, p. 877-882, 1990

15. SOUTHERDEN, P.; GORREL, C. Treatment of a case of refractory feline chronic gingivostomatitis with feline recombinant interferon omega. Journal of Small Animal Practice, v. 48, n. 2, p. 104-106, 2007.

16. WIGGS, R. B. Estomatite Linfocítica_plasmocítica. In: NORWORTHY, G. D.; CRYSTAL M. A.; TILLEY L. P. O paciente feline. São Paulo: Roca, 2009. p. 667-669. 